\title{
FACÇÕES CRIMINOSAS: O CASO DO PCC - PRIMEIRO COMANDO DA CAPITAL
}

Paula dos Santos Bigoli, Eduardo Buzetti Eustachio Bezerro.

Universidade do Oeste Paulista - UNOESTE. Curso de Direito, Presidente Prudente - SP. E-mail: paula.bigoli@hotmail.com

\section{RESUMO}

Este artigo elucida as teorias sobre o surgimento de uma das maiores organizações criminosas do Brasil: o Primeiro Comando da Capital - PCC. Criado na Casa de Custódia de Taubaté-SP por presos que prometiam lutar a favor de seus direitos e contra a opressão do Estado que tinha total descaso com a situação dos presídios do país: superpopulação carcerária, condições desumanas, castigos cruéis e outros fatores foram determinantes para que a revolta fosse instaurada. Ao longo dos 20 anos de sua história, o PCC construiu um império do crime, eliminando seus inimigos, aliando-se a outras facções e conquistando soldados que são fiéis aos mandamentos do "partido", que praticamente monopoliza o crime, tendo em São Paulo, poucos concorrentes a altura.

Palavras-chave: Crime organizado. Facções Criminosas. PCC. Violência. Presídios.

\section{Criminal factions: the case of pcc - primeiro comando da capital (first command of the capital)}

\begin{abstract}
This article shows the theory on the largest criminal organization in Brazil: PCC - Primeiro Comando da Capital (First Command of the Capital). This criminal organization was created in House Custody Taubaté by prisoners who promised to fight for their rights against state repression did not care about the situation of prisons: The prison overcrowding situation, inhumane conditions, the cruel punishments and other key factors for that the revolt began. During its 20 year history, the PCC built a criminal empire by eliminating all enemies, creating alliances with other factions and conquering soldiers today are loyal to the law of "party", having the monopoly of crime in the state of São Paulo, where there are few enemies your height.
\end{abstract}

Keywords: Organized crime. Criminal factions. PCC. Violence. Prisons. 


\section{INTRODUÇÃO}

A ação das facções criminosas é encravada no cotidiano dos brasileiros. Por trás de sequestros, roubos, furtos, tráfico, e vários outros delitos, existem criminosos organizados que atuam no sistema penitenciário e consequentemente fora dele, usando a violência como arma principal para desestabilizar os órgãos de segurança e aterrorizar a sociedade.

Entre os doutrinadores, existem conceitos flexíveis a respeito do crime organizado, porém nenhum é firme em avaliar sua importância, talvez pela dificuldade em classificar um fenômeno tão inesperado. Mendroni (2009), afirma que a grande característica das organizações criminosas é exatamente a "estrutura organizada" capaz de articular, definir ordens e objetivos, além de impor enorme respeito às normas e às autoridades dos líderes. Sustenta ainda que a principal diferença entre uma organização criminosa e um bando ou quadrilha é que esta pratica seus atos de forma improvisada ou desorganizada, enquanto aquela previamente calcula os riscos de uma operação, buscando efetivar resultados seguros.

Mesmo as facções sendo separadas e distribuídas pelos Estados brasileiros, algumas são interligadas e cooperam entre si para a propagação de um mesmo ideal. Segundo Porto (2008), existem inúmeras facções criminosas que atuam no sistema prisional nacional. Entre os principais grupos citados por ele estão "Os manos" e os "Brasas", representando o Rio Grande do Sul; o "Comando Norte-Nordeste" (CNN) originário de Pernambuco; o “Paz, Liberdade e Direito" (PLD) do Distrito Federal; o "Comando Vermelho" (CV), "Amigos dos Amigos" (ADA) e o "Terceiro Comando" (TC) do Rio de Janeiro; e "Comando Revolucionário Brasileiro da Criminalidade" (CRBC), o "Terceiro Comando da Capital" (TCC) e o "Primeiro Comando da Capital" (PCC), criados em São Paulo. Entre as facções citadas, chamo atenção para a última: o "PCC".

O Primeiro Comando da Capital (PCC) é uma facção que, embora tenha surgido no Estado de São Paulo, em pouco tempo se expandiu por todo o território nacional, ganhando espaço na mídia e impondo a sua posição à sociedade. Diante à enorme repercussão gerada a partir de suas ações, torna-se mister compreender a origem do "PCC" e a forma com que ele se tornou uma das maiores e mais poderosas organizações criminosas do Brasil, sendo este, portanto, o objetivo do presente artigo.

Por fim, ressalte-se que o estudo foi desenvolvido a partir de levantamento bibliográfico e documental. Os métodos aplicados foram o dedutivo e o dialético, o que permitiu uma discussão e análise entre 
os fatos apresentados de modo a interpretar possíveis conclusões.

TESES SOBRE O NASCIMENTO DA FACÇÃO CRIMINOSA “PCC”

O grupo autodenominado de "Primeiro Comando da Capital", conhecido pela sigla "PCC" ou "1533" (contagem das letras do alfabeto em forma de números ordinais) surgiu em 1993, na Casa de Custódia de Taubaté-SP, popularmente conhecida pelos detentos como "masmorra", pela severidade no tratamento dos presos. Inicialmente, a facção era integrada pelos fundadores, jogadores do mesmo time de futebol: José Marcio Felício (Geleião), Cezar Augusto Roriz (Cezinha), Idemir Carlos Ambrósio (Sombra), dentre outros, que decidiram formar uma espécie de "partido", com o objetivo de representar os presos na luta a favor dos seus ideais (PORTO, 2008). $\mathrm{Na}$ ocasião, os fundadores formularam um "estatuto" para regular as normas internas do grupo, acrescentando-se, posteriormente, a relação entre o partido e o Comando Vermelho, do Rio de Janeiro. Tal documento foi publicado no Jornal Folha de São Paulo, em 25 de maio de 1997:

ESTATUTO DO P.C.C.

1. Lealdade, respeito, e solidariedade acima de tudo ao Partido.

2. A Luta pela liberdade, justiça e paz.
3. A união da Luta contra as injustiças e a opressão dentro da prisão.

4. A contribuiç̧ão daqueles que estão em Liberdade com os irmãos dentro da prisão, através de advogados, dinheiro, ajuda aos familiares e ação de resgate.

5. O respeito e a solidariedade a todos os membros do Partido, para que não haja conflitos internos, porque aquele que causar conflito interno dentro do Partido, tentando dividir a irmandade será excluído e repudiado do Partido.

6. Jamais usar o Partido para resolver conflitos pessoais, contra pessoas de fora.

Porque o ideal do Partido está acima de conflitos pessoais. Mas o Partido estará sempre Leal e solidário à todos os seus integrantes para que não venham à sofrerem nenhuma desigualdade ou injustiça em conflitos externos.

7. Aquele que estiver em Liberdade 'bem estruturado' mas esquecer de contribuir com os irmãos que estão na cadeia, serão condenado à morte sem perdão.

8. Os integrantes do Partido tem que dar bom exemplo à serem seguidos e por isso o Partido não admite que haja: assalto, estupro e extorsão dentro do Sistema. 9. O partido não admite mentiras, traição, inveja, 
cobiça, calúnia, egoísmo, interesse pessoal, mas sim: a verdade, a fidelidade, a hombridade, solidariedade, e o interesse comum ao Bem de todos, porque somos um por todos e todos por um. 10. Todo o integrante tem que respeitar a ordem e a disciplina do Partido. Cada um vai receber de acordo com aquilo que fez por merecer. A opinião de Todos será ouvida e respeitada, mas a decisão final será dos fundadores do Partido.

11. O Primeiro Comando da Capital - P.C.C. fundado no ano de 1993, numa luta descomunal e incansável contra a opressão e as injustiças do Campo de concentração "anexo" à Casa de Custódia e Tratamento de Taubaté, tem como tema absoluto "a Liberdade, a Justiça e a Paz".

12. O Partido não admite rivalidades internas, disputa do poder na Liderança do Comando, pois cada integrante do Comando sabe a função que lhe compete de acordo com sua capacidade para exercê-la.

13. Temos que permanecer unidos e organizados para evitarmos que ocorra novamente um massacre, semelhante ou pior ao ocorrido na Casa de Detenção em 02 de outubro de 1992, onde 111 presos foram covardemente assassinados, massacre este que jamais será esquecido na consciência da sociedade brasileira. Porque nós do Comando vamos sacudir o Sistema e fazer essas autoridades mudar a prática carcerária, desumana, cheia de injustiça, opressão, torturas, massacres nas prisões.

14. A prioridade do Comando no montante é pressionar o Governador do Estado à desativar aquele Campo de Concentração "anexo" à Casa de Custódia e Tratamento de Taubaté, de onde surgiu a semente e as raízes do comando, no meio de tantas lutas inglórias e a tantos sofrimentos atrozes.

15. Partindo do Comando Central da Capital do KG do Estado, as diretrizes de ações organizadas e simultâneas em todos os estabelecimentos penais do Estado, numa guerra sem trégua, sem fronteira, até a vitória final.

16. O importante de tudo é que ninguém nos deterá nesta luta porque a semente do Comando se espalhou por todos os Sistemas Penitenciários do Estado e conseguimos nos estruturar também do lado de fora, com muitos sacrifícios e muitas perdas irreparáveis, mas nos consolidamos à nível estadual e à médio e longo prazo nos consolidaremos à nível nacional. Em coligação com o Comando Vermelho $\mathrm{CV}$ e PCC iremos revolucionar o país dentro 
das prisões e o nosso braço armado será o Terror "dos Poderosos" opressores e tiranos que usam o Anexo de Taubaté e o Bangú I do Rio de Janeiro como instrumento de vingança da sociedade, na fabricação de monstros.

Conhecemos a nossa força e a força de nossos inimigos Poderosos, mas estamos preparados, unidos e um povo unido jamais será vencido.

LIBERDADE! JUSTIÇA! E PAZ!!!

O Quartel General do PCC, Primeiro Comando da Capital, em coligação com Comando Vermelho CV. UNIDOS VENCEREMOS

Como se pode perceber, o chamado "Primeiro Comando da Capital" não surgiu "do nada". O Brasil tem um longo histórico de incompetência na administração do cárcere, o que durante anos, ocasionou a predominância da violência nas prisões, e de condições de sobrevivência humilhantes. Nesse diapasão, se pronuncia Bittencourt (2010, p.164):

De modo geral, as
deficiências prisionais
compendiadas na literatura
especializada apresentam
muitas características
semelhantes: maus-tratos
verbais (insultos, grosserias
etc.) ou de fato (castigos
sádicos, crueldades
injustificadas e vários
métodos sutis de fazer o
recluso sofrer sem incorrer

em evidente violação do ordenamento etc.); superpopulação carcerária, o que também leva a uma drástica redução do aproveitamento de outras atividades que o centro penal deve proporcionar (a população excessiva reduz a privacidade do recluso, facilita grande quantidade de abusos sexuais e de condutas inconvenientes); falta de higiene (grande quantidade de insetos $\mathrm{e}$ parasitas, sujeiras e imundícies nas celas, corredores, cozinhas etc.); condições deficientes de trabalho, que podem significar uma inaceitável exploração dos reclusos ou o ócio completo; deficiência nos serviços médicos, que pode chegar, inclusive, a sua absoluta inexistência; assistência psiquiátrica deficiente ou abusiva (em casos de delinquentes políticos ou dissidentes pode-se chegar a utilizar a psiquiatria como bom pretexto "cientifico" para impor determinada ordem ou para convertê-lo em um "castigo civilizado"); regime alimentar deficiente; elevado índice de consumo de drogas, muitas vezes originado pela venalidade e corrupção de alguns funcionários penitenciários, que permitem e até realizam o trafico ilegal de drogas; reiterados abusos sexuais, nos quais normalmente levam a pior os jovens reclusos recémingressos, sem ignorar, 
evidentemente, os graves problemas de homossexualismo onanismo; ambiente propicio à violência, em que impera a utilização de meios brutais, onde sempre se impõe o mais forte.

Enquanto a melhoria das prisões caminhava a passos vagarosos, os presos viviam em condições em que é impossível adquirir bons sentimentos: a indiferença da sociedade para com a situação em que eles se encontravam, era certamente o que aumentava a sensação de abandono, desesperança e revolta. Foi aí que ocorreu o estopim: o Massacre do Carandiru, em 2 de outubro de 1992.

Em matéria elaborada por Marina Novaes e Vagner Magalhães, publicada no site Terra, sobre os 20 anos que se passaram desde o evento no Carandiru, a invasão dos policiais que foi motivada por uma briga entre presos que causou uma rebelião, culminou na morte de 111 detentos do Pavilhão 9 da Casa de Detenção de São Paulo (89 aguardavam julgamento e apenas 22 eram condenados), ainda segundo a matéria, no dia do evento o presídio abrigava "7.257 detentos, mais que o dobro de sua capacidade, sendo que 2 mil deles dividiam o espaço do Pavilhão 9". Cumpre salientar que testemunhas oculares dizem que 111 é um número falso, pois no massacre houve muito mais mortes, no entanto, nada é comprovado.

O massacre foi determinante para a conscientização concreta de que algo deveria ser feito para que a engrenagem penitenciária trabalhasse corretamente. No entanto, tal percepção foi tardia. No ano seguinte, como que em resposta ao evento, surgiu o "PCC". Discorre Luiz Flávio Gomes (2014) que "o PCC, hoje um crime organizado muito rico e poderoso, nasceu como resposta à invasão do Carandiru", pondera ainda que "novas facções vão aparecer para protestar contra o massacre jushumanitário que acontece em praticamente todos os presídios brasileiros e latino-americanos".

Em entrevista ao site de notícias "R7", publicada em 30 de setembro de 2012, Alessandra Teixeira, do Instituto Brasileiro de Ciências Criminais alega que o próprio Estado é o culpado pelo surgimento do "PCC", principalmente pela politica que era executada no presídio de Taubaté e no Carandiru.

\section{A EXPANSÃO}

Após a criação do "PCC", iniciou-se um processo de expansão que tinha como objetivo fortalecer a facção. 0 desenvolvimento se deu rapidamente por vários fatores, dentre eles, há as consideradas peças fundamentais, que trataremos a seguir. 
Inicialmente, focou-se na estrutura financeira da organização. Com a realização de assaltos milionários que tinham como maior alvo os bancos, a faç̧ão se estabilizou na compra de armas e drogas. Além disso, a popularização do aparelho celular constituiu fator determinante para que o "PCC" agisse de forma organizada e articulada (DIAS, 2013).

Com a descoberta de que havia se formado uma facção criminosa que pretendia se espalhar dentro dos presídios, as autoridades trataram logo de tomar as medidas cabíveis para separar seus líderes. 0 que não esperavam, é que a medida tivesse efeito reverso: enviando os líderes do grupo para unidades prisionais em outros Estados, eles passaram a disseminar suas ideias aos detentos locais, que passavam a compartilhar dos mesmos objetivos, aliando-se ao "PCC". É - caso da coligação com o "Comando Vermelho", do Rio de Janeiro. A jornalista Fátima de Souza, autora do livro "PCC: a facção", em entrevista ao Grupo Editorial Record, confirma:

Eram apenas duas facções distintas, que se respeitavam, desde que cada uma ficasse em seu próprio território. E foram os governos das duas cidades que colaboraram para que as duas facções formassem uma aliança. $O$ de São Paulo, que querendo "esconder" e enfraquecer a facção, os espalhou pelo país, em especial, no Rio de Janeiro, para onde mandou o então dois chefões do PCC na época: Cesinha (Cesar Augusto Roriz) e Geléia (José Márcio Felício). O governo carioca deu a sua contribuição, não só porque aceitou acolhe-los, mas os colocou no Bangú, ao lado de comandantes do $\mathrm{CV}$, ao lado de Fernandinho Beira Mar. Não demorou para que eles se encontrassem, se conhecessem e se aliassem, descobrindo que unidos teriam mais força. Assim nasceu a união $\mathrm{PCC} / \mathrm{CV}$. As consequências? Passaram a traficar drogas em armas em total sintonia, aumentando seus negócios, trocando armas por drogas e vice-versa. Deixou de existir um limite de "território" com ambas as facções abrindo "espaços" uma para a outra... O PCC pode entrar nos morros cariocas, o CV foi bem recebido nas favelas paulistas. Além disso, montaram um esquema de "proteção" entre eles... bandidos procurados em São Paulo são bem recebidos - e escondidos no Rio de Janeiro e viceversa...

Além dos aliados, o "PCC" contou com um alto escalão de soldados que, recrutados um a um, juram fidelidade ao estatuto da organização e, em troca, recebem a "solidariedade do partido", que fornece aos detentos meios para se viver melhor na 
cadeia (artigos de higiene, roupas, mantas, alimentos, etc.), além de prestar auxílio aos familiares do recluso. $\mathrm{O}$ dinheiro para bancar todo esse companheirismo, vem do crime. Caso a solidariedade do partido não seja motivo suficiente para a lealdade, a severidade das punições para com os integrantes da facção que violem o estatuto, que pode ser até a morte, certamente é um bom pretexto.

Em uma bateria de fugas, resgates, rebeliões, ameaças e assassinatos, o "PCC" alçou o seu poder. Em 2001 a facção organizou o que ficou conhecido como "megarrebelião", em que 29 unidades prisionais do estado de São Paulo se rebelaram ao mesmo tempo. Situação parecida ocorreu em maio de 2006, quando participaram de rebeliões 74 presídios (a diferença é que desta vez, a facção também planejava e executava ataques á forças do Estado e a civis - assassinatos de policiais e agentes penitenciários foram os mais cotados). As rebeliões, por sua vez, tinham reinvindicações padronizadas: pedidos de transferências de detentos e reinvindicações de melhores tratamentos. Além das reinvindicações, o "PCC" aproveitava as rebeliões para assassinar seus inimigos (membros de facções rivais, traidores, delatores, estupradores, justiceiros, e quem mais houvesse motivo) (DIAS, 2013). Aos poucos, orquestrando transferências e eliminando adversários, o "PCC" uniu quem Ihe interessava para que a ascensão fosse obtida.

Não bastasse o caos presente no cotidiano dos paulistas, as autoridades se negavam a admitir que existisse qualquer organização de presos com poder para comandar os eventos que seguiam ocorrendo. Mais uma vez o governo facilitou a expansão do "PCC", deixando que eles evoluíssem silenciosamente (DIAS, 2013).

Hoje, o grande aliado na solidez da organização é o caixa forte. O site de notícias "Último Segundo", divulgou em 04 de fevereiro de 2014, que a polícia conseguiu identificar a lavanderia financeira do "PCC", estimando-se que $\mathrm{R} \$ 200$ milhões de reais, movimentados em cerca de 500 contas bancárias seja o patrimônio da facção (dinheiro arrecadado pelos seus integrantes). Ainda segundo o site, "já se descobriu que parte dos lucros da quadrilha é reinvestida nas operações criminosas e o restante lavado de diferentes formas: mercado financeiro, imóveis, transporte clandestino, comércio ou qualquer atividade que possa ser exercida por terceiros".

\section{MECANISMO LEGAL VIGENTE PARA O COMBATE E EXTINÇÃO DA FACÇÃO}

Em 2001, como que em resposta a “megarrebelião", o governo criou o Regime Disciplinar Diferenciado (RDD), na 
tentativa de desta vez, abalar o "Primeiro Comando da Capital". A tentativa foi falha novamente, uma vez que foi incapaz de impedir as rebeliões que geraram a crise de maio de 2006. Cosate (2009) explica que:

O regime disciplinar diferenciado (RDD) é uma forma de sanção disciplinar que consiste no recolhimento do preso em cela individual, pelo prazo máximo de 360 dias. Nesse período, o detento tem direito a visitas semanais de duas pessoas, sem contar as crianças, com duração de duas horas e igual período diário de banho de sol.

Contudo, Dias (2013) elucida que "a passagem de presos por estes estabelecimentos de regime severo os investe de maior respeito e prestígio junto à massa carcerária, empoderando ainda mais as lideranças do crime organizado".

\section{MUDANÇA ESTRUTURAL E ATUALIDADE}

A facção passou por intensa reforma de seus líderes, situação em que os "fundadores" perderam o comando. Dias
(2013) explica que o "PCC" passou a valorizar a democracia e as tomadas de decisão por uma cúpula de líderes e não mais por um indivíduo. Expõe também que atualmente, as prisões (quase todas dominadas pelo PCC), vivem em momento de "paz", pois os detentos adquiriram maior capacidade de controlar seus impulsos, agindo pela razão e não mais pela emoção.

As autoridades atribuem a liderança atual do "Primeiro Comando da Capital" a Marcos Willians Herbas Camacho, vulgo "Marcola", que atualmente cumpre pena na Penitenciária de Presidente Venceslau/SP, bem como, às pessoas de Julio Cesar Guedes de Morais, o "Juninho Carambola", e outros desconhecidos, que seriam os comandantes das ações da facção. Os novos líderes conscientizaram os seus soldados de que a briga não deveria ocorrer entre eles e após eliminarem seus inimigos, as rebeliões serenaram. Ato contínuo, embora os roubos e furtos continuassem a incidir, os assassinatos pelas ruas diminuíram significativamente, como se pode verificar no gráfico abaixo: 
Gráfico 1. Homicídio doloso por 100 mil habitantes no Estado de SP (2001-2013)

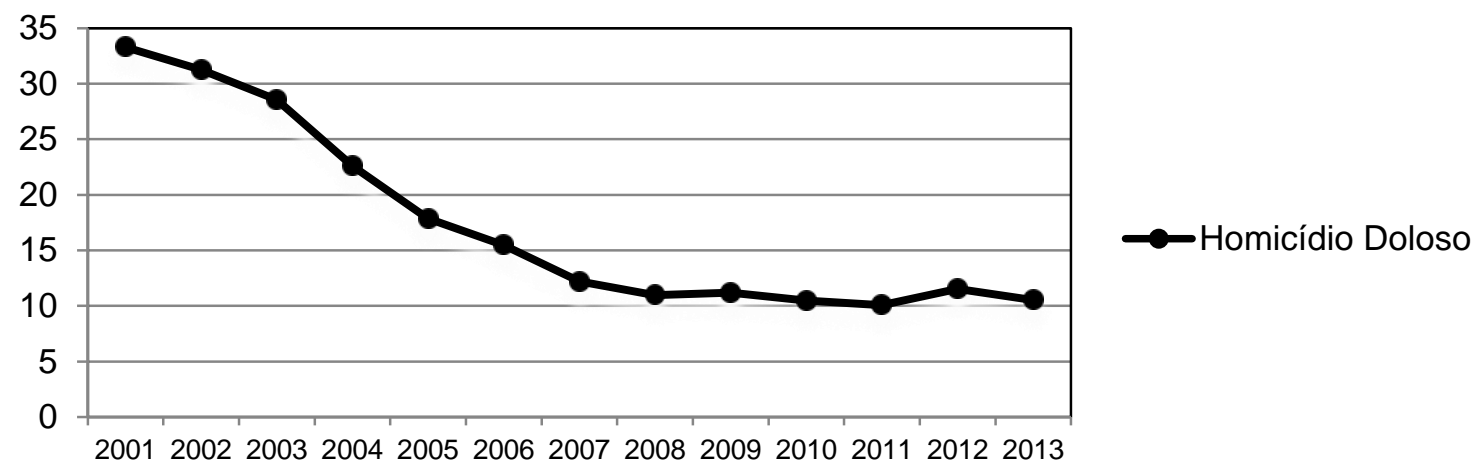

Fonte: Secretaria da Segurança Pública do Estado de São Paulo (http://www.ssp.sp.gov.br).

O Jornal O Estado de S. Paulo, divulgou em 11 de outubro de 2013, o trecho de uma conversa de Marcola com o suposto subordinado "Magrelo" que foi obtida mediante interceptação telefônica feita pelo Ministério Público Estadual:

Ele afirma que "hoje pra matar alguém é a maior burocracia", referindo-se às normas impostas pela facção. Por elas, quando um bandido tem alguma queixa contra outro deve se dirigir a um tribunal do PCC. Neles, o faltoso pode ser desde repreendido até morto. Mas a sentença de morte tem de ser referendada pelo "comando". "Então quer dizer, os homicídios caíram não sei quantos por cento e aí eu vejo o governador chegar lá e falar que foi ele."

O jornal Folha de São Paulo divulgou em 09 de junho de 2006 (um mês após a crise de maio/2006) que Marcola havia confirmado um acordo feito entre o "PCC" e as autoridades em depoimento prestado à "CPI" do Tráfico de Armas. No suposto acordo, autoridades teriam fornecido dois aparelhos celulares para que ele ligasse a outros presos e dissesse que estavam bem, na tentativa que paralisassem as rebeliões que tinham como um dos motivos, o mau tratamento que os detentos transferidos estavam recebendo, passando frio e fome na nova penitenciária.

Há ainda, rumores de que a atual quietude do "PCC" se deve a um suposto acordo junto ao Governo, onde em troca da diminuição de rebeliões e assassinatos, os presídios adotem políticas menos agressivas onde houver a predominação da facção. No entanto, são especulações sem provas concretas.

\section{CONCLUSÃO}

Por alguns instantes, ironicamente, é possível haver confusão em identificar se o 
"PCC" é o lado bom ou ruim da história nascida do cárcere. Colocando-nos no lugar de um detento nos anos 90: violentado e desamparado pelo Estado - que, ao invés de ressocializar criminosos na cadeia, os deixou entregues a própria sorte e os marginalizam ainda mais, permitindo que as prisões recebam mais que o dobro do que suporta de detentos, submetendo-os a condições desumanas e humilhantes, assim como impondo castigos cruéis - que se viu surpreendido por uma organização que estava disposta a ajudar e a zelar pela paz dentro dos presídios, podemos notar que a possível causa do "partido" se mostrava legítima, como se evidencia no vídeo divulgado pela Rede Globo em agosto/2006, onde o representante da facção diz: "não somos contra o governo, mas somos contra a injustiça, abuso de poder, maus tratos, espancamentos e violência há anos às classes pobres nesse País".

Quando o "Primeiro Comando da Capital" surgiu e fundou seu "estatuto", seu ideal chegava a ser romântico: fazer valer a lei que era ignorada pelas autoridades, e lembra-las do significado de "direitos humanos". Mas, tudo isso a que custo? As tarifas pagas pela sociedade foram em forma de violência, assaltos, rebeliões e o preço mais caro: vidas. Como dizia Augusto dos Anjos em sua poesia, "O Homem, que, nesta terra miserável,/Mora, entre feras, sente
inevitável/Necessidade de também ser fera". Contudo, não basta culpar as autoridades competentes. Ora, quem as elegeu, devendo monitorar suas ações e cobrar mudanças, era a sociedade, pois já não estávamos mais na Ditadura, e sim em uma Democracia. Na realidade, o problema nacional nunca foi isoladamente carcerário. A saúde, a educação, o saneamento, e todas as outras áreas do país também sempre foram deficientes e faltosas com os menos favorecidos: os presídios eram um espelho da sociedade.

Assim como nas outras ramificações, em relação aos presídios, a população majoritária não mexeu uma palha sequer para cobrar mudanças, pois afinal, não era dela o problema e sim dos criminosos. Em resposta, o "PCC" impôs a nova realidade: agora o problema é de vocês! Não assiste razão aos criminosos, que tentavam "conquistar a paz de forma violenta", mas em contrapartida, se as autoridades tivessem atendido as suplicas daqueles que sofriam, quiçá nada disso teria acontecido. Para a infelicidade social, o crime e o terror era a linguagem que esses esquecidos possuíam para chamar a atenção e, percebendo que desta forma seus objetivos eram alcançados, não hesitaram em progredir. O fato é que a sobredita facção criminosa se expandiu por todo o território nacional, dominando atualmente grande parte dos presídios, 
coordenando de dentro deles o tráfico de drogas e armas, roubos, furtos, sequestros, golpes, e diversos outros crimes, arrecadando por meio deles, dinheiro suficiente para dar segurança à organização.

O Regime Disciplinar Diferenciado (RDD), a quem o governo atribui a diminuição da criminalidade, de fato não impede a articulação dos líderes e integrantes da facção. Em reportagem exibida no SBT no programa "Conexão Repórter" em 17 de abril de 2014, vídeos supostamente gravados em 2007 (um ano após a crise de maio/2006) na Penitenciária de Presidente Venceslau, mostram "Marcola", "Juninho Carambola" e outros supostos líderes do "PCC" conversando livremente, podendo de acordo com as oportunidades, tramarem qualquer tipo de ação, e disseminar pelos outros presídios, já que é sabença comum que os celulares dificilmente são banidos.

Enfim, a "calmaria" que se instala hoje nos presídios do Estado de São Paulo e a diminuição de mortes nas ruas, seja por conta de acordos, seja por simples liberalidade da facção, tranquilizam mais uma vez a sociedade, que acredita não ser mais possível novas crises como as já causadas.

Completo por dizer que o "PCC" não deve ser ignorado novamente e sim, analisado para que seja extinto. Uma possibilidade para enfraquecer a facção, pode ser justamente encontrada em seu ponto forte: as finanças. Quando a isto, discorre NUNES (s.d.) que "a experiência internacional mostra que atacar os esquemas de lavagem de dinheiro é essencial para a eficácia do combate ao crime organizado". Cita como exemplo a "Camorra", poderosa máfia italiana que teve 357 mil empresas ligadas a ela fechadas, além de perder 400 milhões de euros. As estratégias de soluções certamente são inúmeras, basta saber se as autoridades são capazes de executá-las diante a tamanha desordem e corrupção que se instala no país.

\section{REFERÊNCIAS}

ALVES, C. Organização prega rebelião em presídios. Folha de S. Paulo, 09 jun. 2006. Disponível em: <http://www1.folha.uol.com.br/fsp/1997/5/ 25/cotidiano/29.html>. Acesso em: 09 ago. 2014

BARROS, A. C. Carandiru foi embrião do PCC, mas não único motivo. R7 Notícias, 30 set. 2012. Disponível em: <http://noticias.r7.com/saopaulo/noticias/carandiru-foi-embriao-do-pccmas-nao-unico-motivo-20120930.html>.

Acesso em: 09 ago. 2014.

BITENCOURT, C. Falência da pena de prisão: causas e alternativas. 4. ed. Saraiva, 2010. Disponível em: $<$ http://online.minhabiblioteca.com.br/books /9788502140097>. Acesso em: 26 maio 2014.

COSATE, T. M. Regime disciplinar diferenciado (RDD): um mal necessário? Jus navigandi. 2009. Disponível em: <http://jus.com.br/artigos/12606/regime- 
disciplinar-diferenciado-

rdd\#ixzz39xm8GvPW>. Acesso em: 09 ago.

2014.

DIAS, C. C. N. PCC: hegemonia nas prisões e monopólio da violência. São Paulo: Saraiva, 2013.

ENTREVISTA Fátima de Souza: PCC, a facção. Grupo Editorial Record. Disponível em: <http://www.record.com.b r/autor_entrevista.asp?id_autor=4978\&id_e ntrevista=219>. Acesso em: 09 ago. 2014.

SBT. Escritório central. Conexão repórter. Disponível em:

$<$ http://www.sbt.com.br/conexaoreporter/re portagens/?id=58531>. Acesso em: 09 ago. 2014.

GODOY, M. Foi o PCC quem reduziu a criminalidade, diz Marcola. $\mathbf{O}$ Estado de S. Paulo, 11 out. 2013. Disponível em $<$ http://saopaulo.estadao.com.br/noticias/geral,foi-opcc-quem-reduziu-a-criminalidade-dizmarcola,1084350>. Acesso em: 09 ago. 2014.

GOMES. L. F. Presídios maranhenses: fim de uma era, de uma dinastia. JusBrasil.

Disponível em:

<http://professorlfg.jusbrasil.com.br/artigos/ 121932956/presidios-maranhenses-fim-deuma-era-de-uma-dinastia>. Acesso em: 09 ago. 2014.

MENDRONI, M. Crime organizado: aspectos gerais e mecanismos legais, 3. ed. Atlas, 2009. Disponível em:

$<$ http://online.minhabiblioteca.com.br/\#/boo ks/9788522467013>. Acesso em: 09 ago. 2014.

NOBLAT, R. Globo exibe vídeo do PCC em troca da libertação de repórter. 0 Globo, 13 ago. 2006. Disponível em <http://oglobo.globo.com/pais/noblat/posts/ 2006/08/13/globo-exibe-video-do-pcc-em- troca-da-libertacao-de-reporter-40196.asp>. Acesso em: 09 ago. 2014.

NOVAES, M; MAGALHÃES, V. Carandiru: 20 anos. Terra. Disponível em: $<$ http://www.terra.com.br/noticias/infografic os/carandiru/>. Acesso em: 27 mai. 2014.

NUNES, V. Um pouco mais de inteligência. Época, s.d. Disponível em $<$ http://revistaepoca.globo.com/Revista/Epo ca/0,,EDR76000-6009,00.html>. Acesso em: 17 ago. 2014.

PENTEADO, G. Marcola confirma acordo com o governo, diz deputado. Folha de S. Paulo, 09 jun. 2006. Disponível em <http://www1.folha.uol.com.br/fsp/cotidian/ ff0906200604.htm>. Acesso em: 09 ago. 2014.

PORTO, R. Crime organizado e sistema Prisional. São Paulo: Atlas, 2008. Disponível em:

$<$ http://online.minhabiblioteca.com.br/\#/boo ks/9788522467068>. Acesso em: 09 ago. 2014.

QUADROS, V. Investigação localiza R $\mathbf{2 0 0}$ milhões do PCC em contas de laranjas. Último Segundo, 04 fev. 2014. Disponível em $<$ http://ultimosegundo.ig.com.br/brasil/2014 -02-04/investigacao-localiza-r-200-milhoesdo-pcc-em-contas-de-laranjas.html>. Acesso em: 17 ago. 2014

SERAPIÃO, F. Crime em lugar do Estado: como o PCC pretende dominar o Brasil. Carta Capital. Disponível em $<$ http://www.cartacapital.com.br/blogs/blogdo-serapiao/crime-em-lugar-do-estadocomo-o-pcc-pretende-dominar-o-brasil3006.html>. Acesso em 09 ago. 2014.

SSP. Dados Estatísticos do Estado de São Paulo. Disponível em <http://www.ssp.sp.gov.br/novaestatistica/P esquisa.aspx>. Acesso em: 16 ago. 2014. 
Recebido para publicação em 19/08/2014

Revisado em 10/09/2014

Aceito em 11/09/2014 